\title{
Las competencias gerenciales. Un análisis desde la filosofía de la administración en empresas turísticas
}

\author{
Pedro Ramón-Hernández \\ pedro.hernandez@unicach.mx \\ ORCID: 0000-0002-8696-6572 \\ Universidad de Ciencias y Artes de Chiapas \\ Amada Torres-González \\ Amada.tg@regionsierra.tecnm.mx \\ ORCID: 0000-0003-4674-9175 \\ Instituto Tecnológico Superior de la Región Sierra \\ Néstor Sosa Narváez \\ nestor.sosa@unicach.mx \\ Universidad de Ciencias y Artes de Chiapas
}

\section{RESUMEN}

El objetivo de esta investigación, fue identificar las competencias gerenciales que se desarrollan en empresas turísticas a partir de la filosofía de la administración, a través del rombo filosófico propuesto por Bedard (2003), se buscó reflexionar sobre porqué los gerentes deben enfocar su esfuerzo en un gerenciamiento más humano y de compromiso social. Esta investigación, se realizó con un enfoque cualitativo y de alcance descriptivo, con un estudio de caso en empresas del sector turístico de Palenque, Chiapas, México; el trabajo se centró en tres gerentes, una agencia de viajes, un restaurante y un hotel respectivamente; se identificaron algunas categorías como la experiencia, la inclusión, el compromiso con la sociedad y la calidad, que muestran las formas de gestión que ejercen los gerentes participantes, se concluye que aunque las ciencias administrativas han evolucionado grandemente, aún se practican algunos valores y principios que la administración filosófica contempla y ello explica como algunas personas que aunque no posean amplios conocimientos teóricos sobre la manera de dirigir una empresa, ponen en práctica el sentido humanista al dirigir a su empresa y su personal.

Palabras claves: administración humanista; filosofía; competencias gerenciales. 


\title{
The managerial competences. An analysis from philosophy of the administration in tourist companies
}

\begin{abstract}
This research aimed to identify the managerial competencies developed among tourism companies from the perspective of philosophy of the administration through the philosophical rhombus model proposed by Bedard (2003), aiming to reflect on why managers should focus their effort on more humane management with social commitment. This research was carried out with a qualitative approach and descriptive scope, with a case study in companies in the tourism sector of Palenque, Chiapas, Mexico. The work focused on three managers from a travel agency, a restaurant, and a hotel, respectively. Some categories were identified, such as experience, inclusion, commitment to society, and quality, which showed the forms of management exercised by participating managers. It is concluded that although administrative sciences have yet significantly evolved, some values and principles that the philosophical administration contemplates are still practiced, and this explains how some people who, although do not have extensive theoretical knowledge about how to run a company, satisfactorily achieve to put into practice the humanistic sense when directing their company and internal staff.
\end{abstract}

Keywords: humanistic administration; philosophy; managerial skills.

Artículo recibido: 02 noviembre. 2021 Aceptado para publicación: 28 noviembre 2021 Correspondencia: pedro.hernandez@unicach.mx Conflictos de Interés: Ninguna que declarar 


\section{INTRODUCCIÓN}

Las competencias gerenciales en las empresas del sector turístico son fundamentales para lograr y mantener niveles competitivos importantes, además de contribuir a la generación de diversos beneficios como la generación de empleo y el desarrollo económico y social de las propias empresas y la sociedad donde estas se desenvuelven. Aunque, también es fundamental que las formas en que esas competencias se despliegan, sean apegadas lo más posible a los principios de la filosofía administrativa, dado que esos principios les permitirán a dichas personas, transitar por senderos de lo correcto y de lo que verdaderamente sirve a la misma empresa y a la sociedad que la respalda.

En los últimos años, se ha observado que algunas empresas del sector turístico de la ciudad de Palenque, Chiapas, han descuidado en lo general su enfoque y su nivel de calidad en los servicios que prestan, y esto de alguna manera ha tenido relación con el quehacer gerencial, se percibe la falta de una gestión eficiente y apegada a principios empresariales acorde a las nuevas demandas y a los nuevos tiempos; en respuesta a esta percepción, se realiza esta propuesta que intenta explicar el nivel en que se encuentra la forma de gestión que despliegan estos gerentes, a través del estudio de las competencias gerenciales vistas desde la filosofía de la administración.

Se entiende por competencias gerenciales, "el conjunto de conocimientos, habilidades, comportamientos y actitudes que una persona posee para ser efectiva en las organizaciones" (Sánchez-Valbuena, et al., 2020) para las organizaciones y para quienes desarrollan estas funciones es muy importante que se mantengan elevados los niveles de aprendizaje y profesionalización para generar mejoras sustanciales en dichas empresas. Solo a través de una preparación constante se pueden desarrollar niveles de competitividad importantes en cualquier sector, en este caso el enfoque que se trabajó fue el sector turístico, donde se confluyen empresas del mismo sector, pero con enfoques particulares como hoteles, restaurantes, agencias de viaje, tiendas artesanales, empresas de transporte turístico, incluso servicios complementarios, como tiendas de conveniencia, agencias arrendadoras de autos e información turística; en este sector también intervienen instituciones públicas que están relacionadas a la promoción, fomento y desarrollo turístico, en el caso de Palenque, Secretaria de Turismo del Estado de Chiapas y la dirección de turismo del municipio. 
Palenque recibe alrededor de 400 mil turistas al año, en el primer trimestre de 2021, visitaron Palenque más de 59 mil turistas, entre nacionales y extranjeros (Turismo Chiapas, 2021). Incluso hay alrededor de 100 hoteles entre casas de huéspedes y hoteles a partir de 3 estrellas, cuenta con una gran variedad de restaurantes y agencias de viajes, solo por mencionar las empresas con más acercamiento a los turistas; todo esto nos permite fijarnos un panorama amplio sobre la importancia que tiene el que muchos de los gestores de estas empresas deben poseer las competencias ampliamente comprobadas que les permitan sobresalir de manera significativa con el propósito de brindar un servicio cada vez más amplio y de calidad al turista que visita la región. En la tabla 1 se presentan el número de hoteles que operan en la ciudad de Palenque, número que ha aumentado en los últimos años, aunque aún no aparecen en el registro del Instituto Nacional de Estadística Geografía e Informática (INEGI).

\section{Tabla 1}

Hoteles de Palenque

\begin{tabular}{|c|c|c|c|}
\hline Sector & Denominación & Cantidad & Descripción \\
\hline \multirow[t]{5}{*}{ Hoteles } & Boutique & 1 & $\begin{array}{l}\text { Empresa con } 6 \text { habitaciones muy lujosas y } \\
\text { confortables. }\end{array}$ \\
\hline & Cabañas & 2 & Ubicadas fuera de la ciudad. \\
\hline & Hoteles & 49 & Se clasifican de 3 a 5 estrellas. \\
\hline & Posadas & 44 & $\begin{array}{l}\text { Establecimientos de } 1 \text { y } 2 \text { estrellas, con } \\
\text { servicios básicos. }\end{array}$ \\
\hline & Hostal & 1 & Cuenta son servicios básicos \\
\hline
\end{tabular}

Nota: Elaboración propia con datos de INEGI (INEGI-DENUE, 2014).

Se presentan datos de las empresas hoteleras, aunque el ámbito de la gastronomía es también importante, ya que se existen restaurantes de diversos tipos y tamaños, y en los últimos años este sector ha tenido un avance muy significativo; lo mismo ocurre con las agencias de viajes y transportadoras turísticas, que han aumentado su parque vehicular, incluso lo han modernizado; en lo que respecta a tiendas artesanales, se han diversificado los productos, ya que además de trabajar la piedra, también se ha trabajado con la piel, en tela, en minerales y material duro como el alambre y todo lo que pueda ser manipulado y sirva para representar a la cultura maya. Un aspecto que se ha observado, es la práctica del hospedaje relacionado al campismo, ahora existen empresarios que han optado por vender espacio de terreno, sobre todo los que están cerca de la zona arqueológica, para 
que el turista al que se le denomina como mochilero, rente por noches dicho espacio e instale sus casas de campaña, generando facilidades para el turista porque le resulta barato, y para el empresario porque no invierte.

\section{Fundamentación teórica}

Las competencias gerenciales son un elemento importante para que las empresas sean exitosas, pero es necesario definir un enfoque teórico, sobre cuáles de todas las competencias profesionales, son las que contribuyen en mayor medida a que esas características competitivas sean alcanzadas en las organizaciones, particularmente en las del sector turístico.

En este sentido, se han desarrollado diversos estudios que nos orientan sobre la cuestión. Por lo que es necesario empezar por definir que son y cómo se concibe por si solo el término de competencia, así tenemos que este concepto apareció como una forma de responder ante las demandas del mundo globalizado que traía como exigencia la competitividad en términos de tiempo (Alves et al., 2012). Aunque realmente este concepto tiene su origen desde los aportes de David McClelland de acuerdo con Gross (2008), citado en (Patrón \& Barroso, 2015), el mencionado autor se pudo dar cuenta que por sí solos los test que median la inteligencia no eran suficientes para definir cuando una persona tenía elementos de competencia que pudieran ser valorados como tal, ya que el creía que la verdadera capacidad de una persona era a partir de sus propias características y no tanto de su historial laboral.

En el ámbito turístico y empresarial, las competencias han representado un elemento importante para las empresas que han procurado lograr niveles de competencia global (Abubakar et al., 2019), esto obliga a tener que revisar y replantear esquemas innovadores que garanticen que esas capacidades son parte del mecanismo de avance de las empresas; en este sentido, se buscó identificar cuáles son las competencias que tienen una relación específica en el sector turístico, así, tenemos que para Schein, citado en Raineri (1998), se identifican cuatro competencias: motivación y valores, habilidades analíticas, habilidades interpersonales y habilidades emocionales; por su parte Hellriegel et al., (2008), identifica seis competencias que se relacionan en mayor medida con las organizaciones del sector turístico, estas son: las competencias de trabajo en equipo, de autoadministración, de acción estratégica, de planeación, competencia de multiculturalidad y de comunicación. 
La conceptualización de estas competencias, son: a) el trabajo en equipo; es la capacidad para crear una red activa de relaciones y de trabajar bien con distintos equipos, es crear un entorno saludable en una relación de ganar-ganar; b) la acción estratégica, capaz de formular estrategias efectivas para dirigir a la empresa, c) la autoadministración, consiste en conocerse bien, en saber identificar las propias fortalezas, d) planeación y gestión, revisión regular y ajuste de las empresas para satisfacer necesidades cambiantes, e) competencia multicultural, es estar al tanto de las tendencias en el mundo y tiene que ver de cómo las organizaciones gestionan a partir de los valores y la moral, y f) competencia para la comunicación, que significa escuchar, informar a otros, fomentar canales abiertos y negociar con otros (Hellriegel, et al., 2008).

En este estudio se ha considerado que la gestión gerencial en empresas turísticas es una actividad fundamental para procurar servicios turísticos que garanticen la plena armonía de quienes busca recibir servicios personalizados y que realmente tengan impactos positivos en cada experiencia turística; atendiendo este principio, se hizo una revisión de la literatura acerca de cómo la filosofía de las ciencias administrativas están relacionadas con las actividades turísticas y de cómo los principios o modelos administrativos deben abordarse generando resultados que satisfagan expectativas turísticas.

Para promover los buenos servicios turísticos y considerando al factor humano como elemento central de todo un engranaje organizacional que en la realidad se percibe en servicios diferenciados que las personas en su buena labor proporcionan se tomará como eje principal de estudio, la propuesta de Reneé Bédard (2003), y su rombo filosófico, que recoge lo más esencial de las ciencias administrativas, como lo es el valor de generar servicios orientados hacia la parte humana y no solo en la búsqueda de otros valores como las utilidades económicas, materiales o tecnológicas. A las organizaciones las integran personas, las que deberían ser en la lógica del pensamiento humano lo que más les interese proteger (Arandia \& Portales, 2015), pero también se debe entender que las empresas turísticas, como cualquier tipo de empresa, trabajan en ambientes organizacionales que generan una cultura organizacional propia y particular, la cual es necesario preservar en beneficio de resultados positivos en su quehacer empresarial turístico (Melé, 2003). En síntesis, el rombo de Bédard, permite que no solo la parte dura de las ciencias administrativas intervengan, sino que abre la posibilidad de un análisis multidisciplinario 
y humano de la gestión administrativa Podestá (2006), (citado en Arandia y Portales, 2015).

En este sentido, además de Bédard, se han identificado otros estudios como el de Lombana, quien desarrolló una propuesta sobre las competencias gerenciales a partir del rombo filosófico en mención y que dicho estudio, tiene una relación con la función que desarrollan los gerentes en las empresas turísticas (Lombana et al., 2014); pero debe considerarse también a Arandia y Portales (2015), quienes analizan el mismo rombo de Bédard, desde un enfoque humanista.

El rombo filosófico de Bédard está integrado por cuatro dimensiones: la dimensión praxeológica, la dimensión epistemológica, la dimensión axiológica y la dimensión ontológica.

La praxeología, desde la visión de Bédard, se explica en un sentido amplio que va más allá de la mera acción, esta visión engloba a todos los aspectos de la actividad humana; se incluyen aquí las diferentes conductas humanas, así como las actividades de creación y producción (Bédard, 2003); significa que la persona debe ser capaz de poner en equilibrio todas sus dimensiones, incluyendo la cultural que a la postre lo llevará a desarrollar un sentido más humano (Madrid, 2013), se busca entender la complejidad que desde el inicio representa gestionar personas, como entender los saberes, las habilidades, el comportamiento, los métodos y procedimientos de trabajo. Esta dimensión, tiene relación directa con el quehacer cotidiano de la persona, permite observar de manera plena al individuo y sus diversas respuestas a través de sus habilidades ante cualquier situación que se relacione con su actividad, aquí se conectan los cinco sentidos de la persona, para facilitarse su desempeño.

Por su lado, la epistemología para Bédard (2003), tiene una connotación relacionada a la manera de como dos sujetos distintos comparten el mismo campo de estudio, pero también comprende el estudio de las ciencias y el conocimiento, es decir, se interesa en la teoría de la ciencia general y del estudio de las ciencias observables, las ciencias que intervienen directamente en lo que puede analizarse y describirse, básicamente busca explicar la validez como una manera de darle seriedad al objeto. Busca comprobar, ratificar y en lo general valorar la solidez de los fundamentos intelectuales y conceptuales que se observan en la práctica de parte del individuo, todo ello sin dejar de darle siempre 
el lado humano al desarrollo profesional de cualquier actividad (Arandia \& Portales, 2015).

Siguiendo a Bédard (2003), la axiología, en el rombo filosófico, juega un papel fundamental, porque busca dar una explicación a cerca de la ética y la moral, identifica los valores individuales y colectivos, así como la ética. La moral como se sabe, es un conjunto de reglas de conducta que deben observarse por el individuo; mientras que la ética, se encarga de explicarnos los principios generales de la conducta humana, si bien es cierto el profesional del turismo requiere diversas competencias, pero la cuestión moral incluso espiritual, son fundamentales (Alves et al., 2012), entonces, el papel de la axiología, es la de vigilar de como las personas despliegan una praxeología apegada a los principios y valores que en ese contexto se desarrollen, ejerce un juicio de valor moral y ético en las conductas de las personas.

Para Bédard (2003), no es suficiente la forma praxeológica en que procede una persona, también se requiere que ese proceder sea validado y legitimado por la epistemología y la axiología, pero también es necesario tener un soporte aún más amplio, es aquí donde surge la ontología, la cual trata sobre el conocimiento del ser, es la que sitúa al individuo en los conocimientos de la realidad presente. Es esta dimensión, la que le permite a la persona adentrarse en el conocimiento profundo de una situación en particular. Sobre la ontología, descansan todos los conocimientos necesarios para que la persona pueda desarrollarse con plenitud en sus funciones. Representa el grupo de conceptos, modelos o teorías válidas en un tiempo y en un espacio, a la cual se ciñen muchos procesos científicos y empíricos, dicho de otra forma, la dimensión ontológica le permite al prestador del servicio turístico, entender desde su experiencia y conocimiento teórico, cuales son las necesidades y expectativas que el turista busca cubrir cuando visita un lugar (Arias, 2019) A partir de las aportaciones de Bédard, existen diversos estudios que han usado dicho rombo como base teórica, uno de ellos es el que realizó Lombana et al., (2014), en el que se hace una clasificación de las competencias gerenciales tanto generales como específicas, el estudio refiere sobre diversas competencias, además de usar diversos instrumentos de clasificación, como el proyecto turniting, instrumento validado por diversos organismos; por lo tanto, esta investigación busca retomar los resultados del trabajo de Lombana et al., (2014), que merecen atención y análisis. 


\section{METODOLOGÍA}

\section{Objetivo general}

- Identificar las competencias gerenciales que se desarrollan en empresas turísticas a partir de la filosofía de la administración.

Este estudio se desarrolló con un enfoque cualitativo, de alcance exploratorio y descriptivo (Fernández, 2017), con un marco referencial de estudio de caso (HernandezSampieri, Mendoza; 2018), participaron tres gerentes de tres empresas turísticas, una agencia de viajes, un hotel y un restaurante, cuyas características son catalogadas como las empresas más representativas del sector. Cada gerente entrevistado representa una unidad de estudio, ya que la investigación se centró en cada participante entendiendo que como fuente de información son el elemento más valioso para obtener información confiable, al interpretar sus palabras, gestos y emociones (Flick, 2007).

\section{Categorías de estudio}

Las competencias que se estudiaron en este trabajo son las que propone Hellriegel et, al., (2008), sin embargo, el análisis se hizo a partir del rombo filosófico de Bedard (2003) y el estudio realizado por Lombana et al., (2013), no se estudió en su totalidad cada competencia, sino que se hizo un análisis parcial atendiendo el enfoque humanísticofilosófico que propone el modelo de Bedard, todo ello considerando el contexto de las empresas turísticas a las que se estudiaron.

Para definir las categorías de estudio, en la tabla 2 se presenta un análisis que permite discriminar las competencias gerenciales que se definieron para este este trabajo.

\section{Tabla 2}

Análisis de las categorías de estudio

\begin{tabular}{llcl}
\hline $\begin{array}{c}\text { Competencias que } \\
\text { propone Hellriegel }\end{array}$ & \multicolumn{1}{c}{$\begin{array}{c}\text { Competencias desarrolladas por } \\
\text { Lambana et, al., (2013) }\end{array}$} & $\begin{array}{c}\text { Dimensión del rombo } \\
\text { filosófico al que } \\
\text { pertenece }\end{array}$ & Competencias a estudiar \\
\hline Trabajo en equipo & Habilidades interpersonales & Ontología & Habilidades interpersonales \\
Autoadministración & $\begin{array}{l}\text { Trabajo en equipo } \\
\text { Creatividad } \\
\text { Trabajo en forma autónoma } \\
\text { Ontología }\end{array}$ & $\begin{array}{l}\text { Trabajo en equipo } \\
\text { Creatividad }\end{array}$ \\
& Aprender y actualizarse. & Epistemología & Capacidad de critica y autocritica. \\
& Capacidad de critica y autocritica & Epistemología & \\
& Organizar y planear el tiempo & Praxeología & \\
& Capacidad de adaptación. & Praxeología & Praxeología
\end{tabular}




\begin{tabular}{|c|c|c|c|}
\hline \multirow[t]{6}{*}{ Acción estratégica } & $\begin{array}{l}\text { Motivar y conducir hacia metas } \\
\text { comunes. }\end{array}$ & Ontología & Aplicar conocimientos en la práctica \\
\hline & & Ontología & Liderazgo. \\
\hline & Capacidad de identificar riesgos & Ontología & $\begin{array}{l}\text { Evaluar proyectos empresariales en } \\
\text { diferentes organizaciones }\end{array}$ \\
\hline & Aplicar conocimientos en la práctica. & Praxeología & \\
\hline & Toma de decisiones & Praxeología & \\
\hline & $\begin{array}{l}\text { Evaluar proyectos empresariales en } \\
\text { diferentes organizaciones }\end{array}$ & Praxeología & \\
\hline \multirow{8}{*}{ Planeación } & $\begin{array}{l}\text { Detectar oportunidades para nuevos } \\
\text { negocios. }\end{array}$ & Praxeología & \\
\hline & $\begin{array}{l}\text { Identificar interrelaciones funcionales de } \\
\text { la organización. }\end{array}$ & Ontológica & Conocimiento del área de estudio. \\
\hline & Conocimiento del área de estudio. & Epistemológica & Planeación táctica. \\
\hline & Planeación táctica & Epistemología & $\begin{array}{l}\text { Toma decisiones de inversión, } \\
\text { financiamiento y gestión de recursos }\end{array}$ \\
\hline & $\begin{array}{l}\text { Gestionar sistemas de control } \\
\text { administrativo }\end{array}$ & Praxeología & financieros en la empresa. \\
\hline & $\begin{array}{l}\text { Tomar decisiones de inversión, } \\
\text { financiamiento y gestión de recursos } \\
\text { financieros en la empresa. }\end{array}$ & Praxeología & \\
\hline & $\begin{array}{l}\text { Mejorar e innovar los procesos } \\
\text { administrativos. }\end{array}$ & Praxeología & \\
\hline & $\begin{array}{l}\text { Administrar la infraestructura } \\
\text { tecnológica de una empresa. }\end{array}$ & Praxeología & \\
\hline \multirow[t]{4}{*}{ Multiculturalidad } & $\begin{array}{l}\text { Responsabilidad social y compromiso } \\
\text { ciudadano. }\end{array}$ & Axiología & $\begin{array}{l}\text { Responsabilidad social } \quad y \\
\text { compromiso ciudadano. }\end{array}$ \\
\hline & Compromiso y medio ambiente. & Axiología & Compromiso ético. \\
\hline & Compromiso y medio cultural. & Axiología & $\begin{array}{l}\text { Valoración y respeto por la } \\
\text { diversidad y multiculturalidad. }\end{array}$ \\
\hline & $\begin{array}{l}\text { Valoración y respeto por la diversidad y } \\
\text { multiculturalidad }\end{array}$ & Axiología & \\
\hline \multirow{5}{*}{ Comunicación } & Compromiso ético. & Axiología & \multirow{3}{*}{$\begin{array}{l}\text { Competencias para procesar } \\
\text { información. } \\
\text { Comunicación oral y escrita. }\end{array}$} \\
\hline & Abstracción y análisis. & Epistemología & \\
\hline & $\begin{array}{l}\text { Competencias para } \quad \text { procesar } \\
\text { información. }\end{array}$ & Epistemología & \\
\hline & Comunicación oral y escrita. & Praxeología & \\
\hline & Comunicación en un segundo idioma. & Praxeología & \\
\hline
\end{tabular}

Nota: Elaboración propia

\section{Sujetos de estudio}

En la ciudad de Palenque, Chiapas existen alrededor de 100 establecimientos de hospedaje, así como 120 establecimientos dedicados a la producción y venta de alimentos y bebidas, también se cuentan 6 agencias de viajes. A partir de estos datos y en atención 
al enfoque filosófico con que se desarrolló esta investigación, se trabajó con tres gerentes de empresas del sector turístico; con ello se buscó tener un resultado orientado a como dichos gerentes gestionan estas empresas dedicadas al servicio turístico desde un ámbito humanista.

\section{Validación de categorías de estudio e instrumento de investigación}

Las categorías de estudio fueron las que propone Hellriegel et al., (2008), es decir, autoadministración, trabajo en equipo, comunicación, planeación, acción estratégica y multiculturalidad; tales categorías se contrastaron con las categorías del estudio de Lombana et al., (2013). Las más relevantes son: creatividad, trabajo en forma autónoma, organizar y planear el tiempo, capacidad de adaptación, habilidades personales, liderazgo, capacidad de identificar riesgos, toma de decisiones, evaluar proyectos empresariales en diferentes organizaciones, detectar oportunidades para nuevos negocios, identificar interrelaciones funcionales de la organización, planeación táctica, gestionar sistemas de control administrativo, mejorar e innovar procesos administrativos, responsabilidad social y compromiso ciudadano, valoración y respeto por la diversidad y multiculturalidad y comunicación y escrita. Además de hacer una revisión exhaustiva de artículos científicos sobre estudios relacionados a la temática en cuestión.

A partir de las categorías referidas, se diseñó un cuestionario de doce preguntas semiestructuradas; aplicando una pre entrevista a un empresario local no relacionado con el sector turístico; después de la corrección que tuvo que ver con estilos de redacción, se desarrollaron tres entrevistas a igual número de empresarios del sector turístico, es decir, un gerente de agencia de viajes, un gerente de hotel y un gerente de restaurante.

\section{RESULTADOS Y DISCUSIÓN}

\section{Se entrevistaron a tres gerentes del sector turístico, cuyos perfiles son:}

a) Gerente 1: es gerente de front desk de un hotel desde hace 5 años, tiene amplia experiencia en la actividad hotelera, tiene una licenciatura en el área de turismo, tiene además del área de ventas del hotel actual, otras dos unidades que pertenecen al mismo corporativo, todas en la atención al turismo.

b) Gerente 2: es licenciada en turismo, ha laborado en hoteles y restaurantes y actualmente tiene un año y medio de estar como gerente de la agencia de viajes.

c) Gerente 3: es licenciada en administración de empresas, tiene un año y medio de ser la gerente del restaurante, ya ha laborado en otras empresas del mismo giro. 
Después de la aplicación de entrevistas, se procedió a analizar los resultados usando el software ATLAS.TI versión 8.2.4.

En la tabla 3, se presentan las categorías y subcategorías encontradas en este estudio.

Tabla 3

Tabla Resultados

\begin{tabular}{lclc}
\hline \multicolumn{1}{c}{ Categorías } & Frecuencias & \multicolumn{1}{c}{ Subcategorias } & Frecuencias \\
\hline Acción estratégica & $\mathbf{4 2}$ & Calidad & $\mathbf{2 0}$ \\
& & Competitividad & 3 \\
& & Atencion al cliente & 11 \\
Autoadministración & \multirow{2}{*}{15} & Emprendimiento & 2 \\
Comunicación & & Solución de problemas & 7 \\
Multiculturalidad & $\mathbf{3 2}$ & Experiencia & $\mathbf{1 1}$ \\
& 6 & Empatía & 10 \\
Planeación & \multirow{2}{*}{} & Inclusión & $\mathbf{1 0}$ \\
& $\mathbf{2 9}$ & Compromiso son la sociedad & 7 \\
Trabajo en equipo & & Finanzas & 5 \\
& \multirow{2}{*}{25} & Gestión & $\mathbf{2 4}$ \\
& & Ventas & 7 \\
& & Colaboración & 6 \\
& & Compromiso & $\mathbf{2 5}$ \\
& & Confianza & 4 \\
& & Empoderar & 3 \\
& & Liderazgo & 9 \\
\hline
\end{tabular}

Nota: Elaboración propia

De las seis categorías originalmente buscadas, resaltan tres, la acción estratégica, la comunicación y la planeación como las que más menciones tuvieron en el proceso investigativo, las tres categorías no tienen alta relevancia; sin embargo en el caso de las subcategorías deben mencionarse el compromiso, la gestión, la calidad, la experiencia y la inclusión como subcategorías que nos permiten visualizar los primeros resultados con mucho significado, sobre todo en el enfoque del rombo filosófico que en este estudio se usa.

Respecto a los resultados visibles y plasmados en las redes conceptuales, a continuación, se presentan las tres redes que mejor muestran los resultados obtenidos. En la figura 1, se presenta la red de la categoría autoadministración, se eligió esta red, ya que es una de las categorías que más integró a las otras categorías en el proceso investigativo con los gerentes participantes. 
Figura 1: Autoadministracion

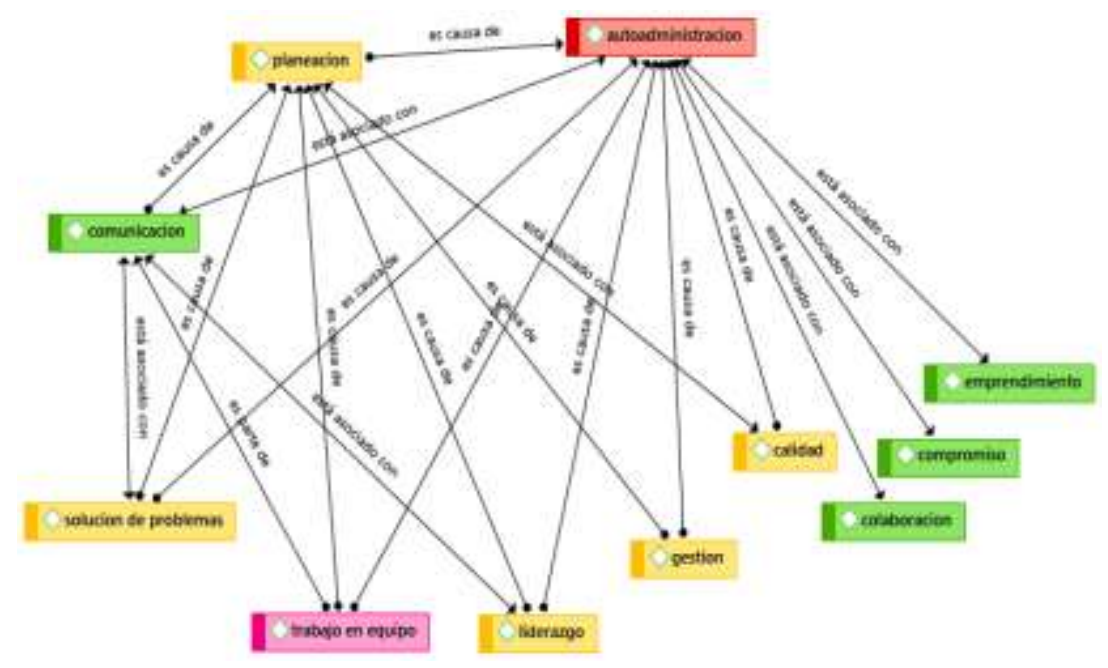

Nota: Elaboración propia con apoyos de ATLAS. Ti 8. 2.4

Se observa como la autoadministración implica un proceso comprometido de los gerentes entrevistados, incluye procesos de planeacion, de comunicación y de trabajo en equipo; pero lo más importante es que involucra subcategorias que tienen relación con el compromiso de tales gerentes como por ejemplo su profesionalismo en la actividad del turismo (Alves et al., 2012).

"Saber que se van satisfechos, que se van contentos, que realmente es lo que ellos esperaban, he en relaciona a calidad precio que se vayan viendo que no los desangramos" (Gerente 1 [1:47]).

En la figura 2, se presenta la red correspondiente a la categoria de trabajo en equipo, que resaltó por los aspectos que más se observaron durante el análisis de las entrevistas.

Figura 2: trabajo en equipo.

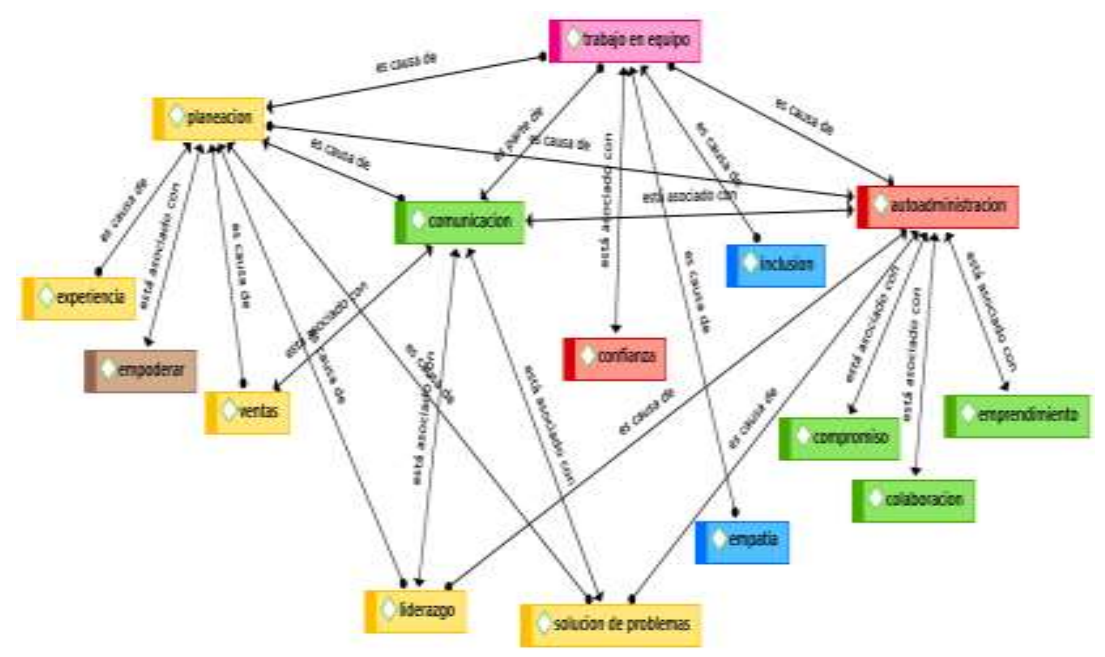

Nota: Elaboración propia con apoyos de ATLAS. Ti 8. 2.4 
En el trabajo en equipo, los gerentes mostraron relación amplia con categorias y subcategorias, como planeación, comunicación y autoadministracion; pero llama la atención una subcategoría relacionada a la multicultiralidad, la inclusión, que permite deducir la filosofia humana con la que se conducen en su actividad gerencial.

"El trabajo en equipo no debe estar afuera de ninguna forma... evalúo mi capacidad de trabajo en equipo por la comunicación que tengo con mis colaboradores, con mi equipo con mi personal, esa comunicación que hay ese respecto, no es tenemos que trabajar" (Gerente 3 [3:33]).

Por último, se presenta en la figura 3 la red conceptual de la acción estrategica, dado que fue la categoría con más menciones de parte de los tres gerentes entrevistados.

Figura 3: acción estrategica

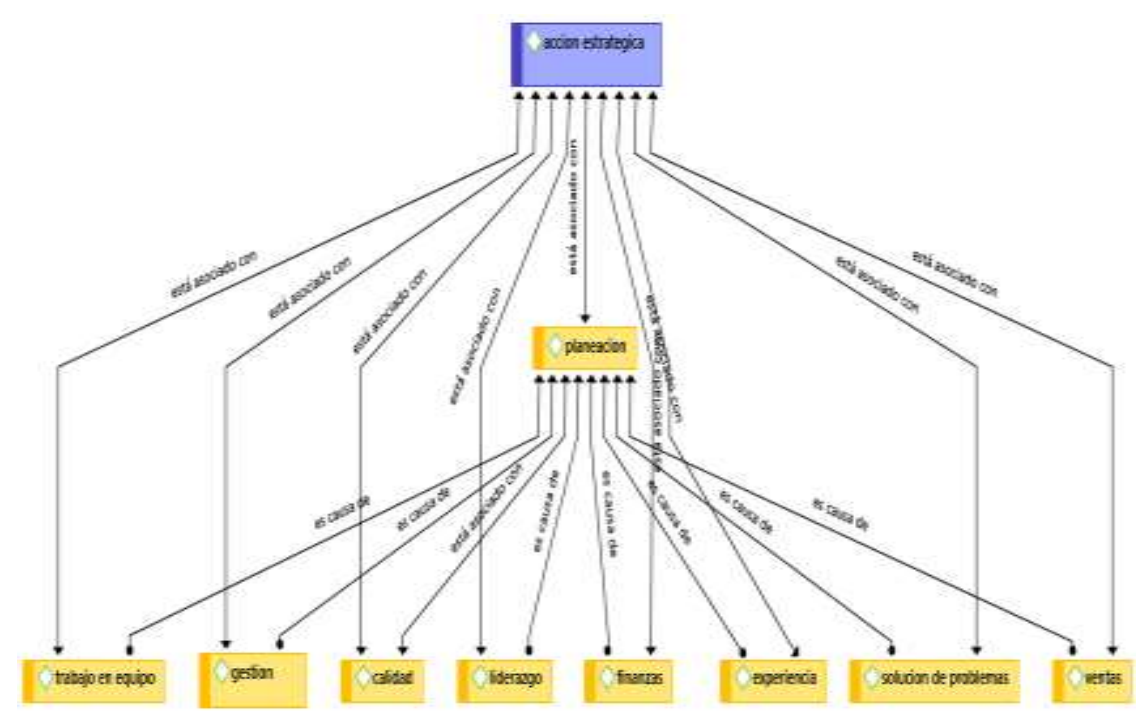

Nota: Elaboración propia con apoyos de ATLAS. Ti 8. 2.4

Aunque esta categoría solo incluye a la planeacion y el trabajo en equipo, es importante porque permitió entender como los gerentes participantes en este estudio manejan diversos conceptos relacionados a la filosofia de la administracion y del quehacer gerencial actuales. Ese quehacer se refiere a la constante toma de decisiones, pero que estan relacionadas con la parte humana y sensible más alla de aspectos tecnicos o numéricos (Aristimuño \& Guaita, 2011).

"Estamos muy comprometidos porque como le decía nuestra mejor fuente de ventas son las recomendaciones, que nos hacen con sus amigos, familias, con los compañeros de trabajo, etc. Por eso estamos 
comprometidos con el servicio de calidad con nuestros clientes"

(Gerente $2[2: 8])$.

Como se ha podido observar tanto en la tabla de resultados como en las redes presentadas; las categorias estudiadas en los tres gerentes participantes, tienen una relación significativa con el rombo de Bedard (2003). Dicho rombo se integra de cuatro grandes dimensiones; la praxeologia, la epistemologia, la axiologia y la ontologia; por su lado el estudio realizado por Lombana et al., (2013), trae a cuentas las competencias genéricas y específicas que los gerentes pueden desarrollar en contextos también específicos; pero debe entenderse que esos contextos son altamente cambiantes, además de generarse diversas adaptaciones a partir de como desde la filosofía de la administración son percibidos y más aún, como se desarrollan tales competencias, de ahí que los resultados observados en este estudio presentan similitudes que son propias de la función turística en donde se realizó en el estudio.

En este sentido y a partir de la categoría de comunicación, se encontró como subcategoría a la empatía que a su vez se relaciona con las dimensiones axiológica, epistemológica y praxeológica (Lombana et al., 2013; Bedard, 2003); en la categoría trabajo en equipo, se encontró a la colaboración, al compromiso, la confianza, el empoderamiento y el liderazgo, que tienen relación con la ontología, aquí es necesario resaltar que el contexto es fundamental, porque es la categoría que las subcategorías genero además de tener una relación solo con la dimensión que en la práctica genera trabajo verdadero en conjunto gerentes y colaboradores.

La categoría autoadministración, generó las subcategorías solución de problemas y experiencia, que se relacionan con la dimensión praxeologica y ontológica; ambas dimensiones permitieron observar en los gerentes participantes, una actitud que pone de manifiesto lo que estas dimensiones generan en las personas que se apoyan en su sentido humano de gerenciamiento; por el lado de la categoría de acción estratégica, se observaron a la calidad, la competitividad, la atención al cliente y el emprendimiento, estas se relacionan con la ontología, de alguna manera en esta categoría se esperaba un resultado parecido.

La planeación, generó subcategorías como las finanzas, la gestión y las ventas, relacionadas a la dimensión ontológica y epistemológica, en el caso de la epistemología se observa como los gerentes, a través de la experiencia, poseen un sentido epistémico 
que permite percibir un conocimiento de la propia acción turística, que permite visualizar una actitud de servicio en una comprensión amplia del quehacer turístico desde su propia concepción (Muñoz, 2014). Por su parte, la multiculturalidad permitió observar a las subcategorías inclusión y compromiso con la sociedad, relacionadas a la praxeologia y la axiología, en el caso de la segunda dimensión, se consideraba que el contexto podría generar otra realidad, sin embargo los resultados hablan de una mentalidad amplia y global que ha ayudado a generar aceptación hacia un mundo diverso en sus diversas formas de desarrollo social y humano, sobre todo la cultural (Mundo et al., 2016).

\section{CONCLUSIONES}

Como se dijo antes, ¿cómo explicamos que algunas ocasiones se observan personas con altos niveles de preparacion academica pero que no poseen el modo fino de gerenciar, de dirigir, de liderar y por el contrario otras personas que no tienen estos altos niveles de conocimiento desde la teoria, si ofrecen resultados y logran que sus colaboradores esten motivados, que generen trabajo en equipo y que ejerzan procesos de planeacion y estrategicos adecuados, la respuesta podria estar en su filosofia personal relacionada a los viejos canones de la administracion humanista (Bedard, 2003).

En este estudio se comprobó que la idea de Reneé Bedard tiene lógica y genera algún nivel de confianza en que a pesar de tantos procesos relacionados al uso de la tecnologia y la vertiginosa avalancha de procesos de desarrollo modernos que exigen a los gerentes actuales trabajar desproporcionadamente y a contratiempo, por una competencia que muchas veces no tiene razon de ser ni tampoco lleva a nada bueno para las personas, aun apoyarse en la gestion humana genera resultados humanos, que aunque desasceleren el crecimiento economico en las empresas, si aceleran lo más esencial que es su sentido del servicio y de la atencion a los demas, aspecto tan necesario en los tiempos actuales y turbulentos.

Las competencias gerenciales que más fueron observadas en este estudio son la calidad, la experiencia, la gestión, la inclusión y el compromiso. De estas subcategorias emergentes y a partir del rombo de Bedard, se puede afirmar que el compromiso, la experiencia y la inclusión son las que generan mejores resultados en el sentido humano a las empresas donde laboran los gerentes participantes, son estas subcategorias que a partir de la categoria con mayor mención como fue el trabajo en equipo que ayudan a desarrollar 
un sentido más humano en la gestion de estas empresas del sector turistico de Palenque, Chiapas.

\section{REFERENCIAS BIBLIOGRAFICAS}

Abubakar, M., Hamzah, E., Maher, A., \& Alev, E. (2019). Knowledge management, decision-making style and organizational performance. Journal of Innovation and Knowledge, 4, 104-114. https://doi.org/https://doi.org/10.1016/j.jik.2017.07.003

Alves, T., Marreiro, M., \& Duarte, M. (2012). Competencias y habilidades necesarias de los gestores de hoteles de lujo y superlujo. Un estudio de caso en el Polo Turistico Via Costeira, Natal, Brasil. Estudios y Perspectivas En Turismo, 21(3), 604-620. https://www.redalyc.org/articulo.oa?id=180724044004

Arandia, O., \& Portales, L. (2015). Fundamentos de la gestión humanista: Una perspectiva filosófica. AD-Minister, 26, 123-147. https://doi.org/10.17230/administer.26.6

Arias, E. (2019). Análisis conceptual del turismo: hacia su visión ontológica. September 2019, 391-405. https://doi.org/10.11606/issn.1984-4867

Aristimuño, M., \& Guaita, W. (2011). Las Competencias Gerenciales en la Gestión de Instituciones de Educación Superior. Posgrado Y Sociedad. Revista Electrónica, 11(2), 66-81. https://revistas.uned.ac.cr/index.php/posgrado/article/view/2224

Bédard, R. (2003). El Rombo Y Las Cuatro Dimensiones Filosóficas. AD-MINISTER Universidad $\quad$ EAFIT, $\quad 3, \quad 68-88$. https://www.researchgate.net/publication/279472702_

Fernández, S. (2017). Si las piedras hablaran. Metodología cualitativa de Investigación en Ciencias Sociales. La Razon Historica, 37, 4-30. www.revistalarazonhistorica.com

Flick, U. (2007). El diseño de Investigacion Cualitativa. (Morata (ed.)). https://dpp2017blog.files.wordpress.com/2017/08/disec3b1o-de-lainvestigacic3b3n-cualitativa.pdf

Lombana, J., Cabeza, L., Castrillón, J., \& Zapata, A. (2013). Formación en competencias gerenciaes. una mirada desde los fundamentos filosóficos de la administración. Estudios $\quad$ Gerenciales, 30, 301-313. http://www.redalyc.org/articulo.oa?id=21226279011

Madrid, J. (2013). La praxeología: una propuesta educativa de formación humana para la 
resignificación de la persona. Revista Educación y Desarrollo Social, 7(2), 5671. https://doi.org/10.18359/reds.680

Melé, D. (2003). The Challenge of Humanistic Economics. Journal of Business Ethics, 44, 77-88. https://doi.org/10.2307/1058699

Mundo, R., Gómez, C., \& Mundo, J. (2016). Vocación del turismo multicultural: grupos étnicos en Chiapas. RITUR. Revista Iberoamericana de Turismo, 6(Especial), 144-156. https://doi.org/10.2436/20.8070.01.19

Muñoz, F. (2014). La epistemología y el turismo. Turismo y Sociedad, 15, 187. https://doi.org/10.18601/01207555.n15.11

Patrón, R., \& Barroso, F. (2015). Competencias directivas de gerentes de restaurantes turísticos. un estudio en la ciudad de San Francisco de Campeche, Mexico. Estudios y Perspectivas En Turismo, 24(1), 96-114. http://www.redalyc.org/articulo.oa?id=180732864006\%0ACómo

Raineri, A. (1998). Habilidades Gerenciales: Análisis De Una Muestra de Administradores En Chile. Abante, 1(2), 213-233. https://www.researchgate.net/publication/5224115\%0AHABILIDADES

Sánchez-Valbuena, I., Sánchez-González, J., \& Pinedo-Frías, A. (2020). Competencias Gerenciales Factor de Éxito en Empresas de Servicios Públicos. Saber, Ciencia y Libertad, $\quad$ 15(2), 74-90. https://doi.org/10.18041/23823240/saber.2020v15n2.6716

Turismo, S. de, \& Chiapas. (2021). Marzo 2021. 